Research Article

\title{
Simulation and Experimental Tests of Ballistic Impact on Composite Laminate Armor
}

\author{
Ali Murat Soydan (D, ${ }^{1}$ Bahadır Tunaboylu, ${ }^{2}$ Ahmed Galal Elsabagh, ${ }^{2}$ Abdul Kadir Sarı, ${ }^{3}$ \\ and Recep Akdeniz ${ }^{3}$ \\ ${ }^{1}$ Institute of Energy Technologies, Gebze Technical University, Gebze, Kocaeli, Turkey \\ ${ }^{2}$ Department of Industrial Engineering, Dragos Kampusu Orhantepe Mahallesi, Istanbul Sehir University, Turgut Ozal Bulvarl, \\ No. 21, Dragos, Kartal, Istanbul, Turkey \\ ${ }^{3}$ Department of Materials Science and Engineering, Gebze Technical University, Gebze, Kocaeli, Turkey
}

Correspondence should be addressed to Ali Murat Soydan; asoydan@gtu.edu.tr

Received 3 May 2018; Revised 5 July 2018; Accepted 23 July 2018; Published 23 August 2018

Academic Editor: Jose Cesar de Sa

Copyright (c) 2018 Ali Murat Soydan et al. This is an open access article distributed under the Creative Commons Attribution License, which permits unrestricted use, distribution, and reproduction in any medium, provided the original work is properly cited.

\begin{abstract}
This paper presents the experimental testing and simulation results of ballistic impact tests on laminated armor samples that consist of three layers of different materials: fiber-cement, Kevlar fabric, and steel. In experimental tests, a 9 mm FMJ bullet was launched towards a $100 \mathrm{~cm}^{2}$ sample of the armor from the fiber-cement side. Ansys Workbench Explicit Dynamics and Ansys AUTODYN 3D were used to model and simulate the ballistic impact. Experimental testing and simulation results were compared to analyze the behavior of composite armor designs, and a good agreement was observed.
\end{abstract}

\section{Introduction}

The purpose of armor systems is preventing entry of bullets into the protected area. The armor to be used should be durable and easy to produce, use, and repair. The traditional method of armoring is the use of thick steel plates. However, multilayer armor was developed in decades and improved penetration resistance/weight ratio relative to steel. In multilayered armors, the outer ceramic layer deflects the bullets, the artificial fibers hold the bullet particles, and the metal part stops the bullets. This kind of armor systems significantly less weigh than one-layer solid steel armors providing equivalent protection [1]. Enhancing the ballistic resistance of armors by using composite materials is a generally accepted practice in armor design. In the past few decades, laminate armors have been investigated to achieve good durability and lightweight armors [2]. Kevlar and steel are commonly used materials in ballistic armor industry especially in structural armor types [3,4]. Armor design is typically performed in two stages especially for those that contain multiple stacks for maximum efficacy. First steps of this stage are the armor design and selection of appropriate materials for the application and the threat under consideration. Second stage includes simulation and testing the structure which define the ballistic limits of the materials being used in designing the armor and total efficiency of the design [5].

According to EN 1063 Ballistic Standards in Table 1, there are different types of projectiles and testing conditions of the ballistic test. Tests are classified into levels listed from BR1 to BR7 based on the geometry, the tip shape, the shooting distance, the mass, the speed, and the material of the projectile.

There are two major applications of ballistic armors, the body armor and the structure armors. In the battlefield, humans are usually encountered BR2 level of threat, while vehicles and buildings are encountered a higher level of threat. Material type, geometry, application, and working conditions are the key parameters of the armor design. In the simulation process, the modeling conditions of both target and projectile are playing an important role in the results. Meshing tool, mechanical properties, and physical 
Table 1: Ballistic standards [6].

\begin{tabular}{|c|c|c|c|c|c|c|}
\hline \multicolumn{7}{|c|}{ CEN (Committee European Normalization) BS/EN 1063 Ballistic Standards } \\
\hline Level & Gun Type & Core Type & Caliber & Mass (gr) & Shooting distance $(\mathrm{m})$ & Bullet speed $(\mathrm{m} / \mathrm{s})$ \\
\hline BR1 & Riffle & $0.22 \mathrm{LR}$ & $\mathrm{L} / \mathrm{RN}$ & $2.6 \pm 0.1$ & $10.00 \pm 0.5$ & $360 \pm 10$ \\
\hline BR2 & Hand gun & $9 \mathrm{~mm}$ parabellum & FJ1/RN/SC & $8.0 \pm 0.1$ & $5.00 \pm 0.5$ & $400 \pm 10$ \\
\hline BR3 & Hand gun & 0.357 magnum & $\mathrm{FJ} 1 / \mathrm{CB} / \mathrm{SC}$ & $10.2 \pm 0.1$ & $5.00 \pm 0.5$ & $430 \pm 10$ \\
\hline BR4 & Hand gun & 0.44 magnum & FJ2/FN/SC & $15.6 \pm 0.1$ & $5.00 \pm 0.5$ & $440 \pm 10$ \\
\hline BR4+ & Riffle & $7.62 \times 39 \mathrm{~mm}$ & $\mathrm{FJ} 2 / \mathrm{PB} / \mathrm{HC} 1$ & $8.0 \pm 0.1$ & $10.00 \pm 0.5$ & $710 \pm 10$ \\
\hline BR5 & Riffle & $5.56 \times 45 \mathrm{~mm}$ & $\mathrm{FJ} 2 / \mathrm{PB} / \mathrm{SCP} 1$ & $4.0 \pm 0.1$ & $10.00 \pm 0.5$ & $950 \pm 10$ \\
\hline BR6 & Riffle & $7.62 \times 51 \mathrm{~mm}$ & FJ1/PB/SC & $9.5 \pm 0.1$ & $10.00 \pm 0.5$ & $830 \pm 10$ \\
\hline BR6+ & Riffle & $5.56 \times 45 \mathrm{~mm}$ & $\mathrm{FJ} / \mathrm{PB} / \mathrm{SC}$ & $3.6 \pm 0.1$ & $10.00 \pm 0.5$ & $980 \pm 10$ \\
\hline BR7 & Riffle & $7.62 \times 51 \mathrm{~mm}$ & $\mathrm{FJ} 2 / \mathrm{PB} / \mathrm{HC} 1$ & $9.8 \pm 0.1$ & $10.00 \pm 0.5$ & $820 \pm 10$ \\
\hline
\end{tabular}

L: lead; CB: conic bullet; FJ: full steel jacket; FN: flat nose bullet; RN: rounded nose bullet; HC1: steel hard core with incendiary; SCP1: soft core with steel penetrator; PB: pointed bullet; SC: soft core.

properties of the materials and material modeling characterizing like the type of elasticity and failure conditions are the most important modeling conditions in ballistic armor simulation process $[6,7]$.

Commercial software tools like SolidWorks, CATIA V5, and Ansys design modeler are commonly used to model the geometry of both armor and projectile. While tools like ABAQUS, Ansys with LS-DYNA, and AUTODYN 3D are used for material and test modeling $[8,9]$.

In this study, composite-layered laminate armor structures were designed, and test samples were manufactured. Simulations, as well as experimental tests at BR2 ballistic level, were performed, and results are presented.

\section{Experimental Conditions and Results}

2.1. Armor Structure. The composite structures consisted of layers of Kevlar 29 fabric of $200 \mathrm{~g} / \mathrm{m}^{2}, 1 \mathrm{~mm}, 1.5 \mathrm{~mm}$, or $3 \mathrm{~mm}$ thick S235JR metal sheets and a fiber-cement layer. HEXION MGS L285 resin impregnated with MGS H160 hardener was used for bonding the materials assembly. The damage in composite laminates at BR2 level ballistic impact with shear wave velocity in the target of $2 \mathrm{~mm} / \mu \mathrm{sec}$ is localized within a zone of $3-10 \mathrm{~cm}$ near the impact area; therefore, samples with $10 \mathrm{~cm} \times 10 \mathrm{~cm}$ were found to be sufficient to test the ballistic behavior of the laminate structure [10]. The samples were performed by pressing with $10-20$ bar pressure at $60^{\circ} \mathrm{C}$ for 10 minutes with a hydraulic press.

The structure has a targeted special design of fibercement board bonded to a steel plate via Kevlar, and an optimization study was carried out. The composite laminates were produced for add-on armored protection in prefabricated structures or buildings where the fiber-cement layer plays as a front layer which look alike the structure wanted to be protected, Kevlar layer as an aid layer to slow down the bullet, and steel layer to stop the bullet. Add-on systems will make it easier to repair structures in areas under attack. Only deformed plates will be removed and replaced with new ones. To provide protection with the cheapest and most common materials in the market, S235JR steel sheets, Kevlar 29, cellulose fibers, and fiber-cement were preferred. It was aimed to provide maximum protection at BR2 level with minimum weight, so fiber-cement and Kevlar fabrics were kept same for all samples and minimum metal sheet thickness for maximum protection was tried to be found.

2.2. Test Conditions. The produced composite armor samples were tested at the BR2 ballistic level against Parabellum $9 \mathrm{~mm}$ round tip, soft core bullet projectile which was shot towards the fiber-cement layer at the ballistic laboratories of Makina Kimya Enstitusu (MKE) in Ankara. The bullets were placed in the machine shown in Figure 1, and shooting was made at $5 \mathrm{~m}$ distance to the composite armor specimens mounted in the center of $50 \times 84 \times 3 \mathrm{~mm}$ (Figure 2) metal board. The middle of the metal plate was cut to size $10 \times 10 \mathrm{~cm}$ so as not to interfere with the armor feature. The produced armor is attached to the metal plate with the help of Z-shaped clamps (Figure 2). The left of the clamps is stationary, but the right side can be adjusted at the desired distance on the move and can be fixed in the position specified after the armor is placed. So that when the bullet hits the armor after the ignition, the firmly positioned armor does not move and keeps the impact entirely on itself.

\section{Modeling and Impact Simulation}

3.1. Modeling Methodology. The armor has been modeled with Ansys Workbench v18.2 and 19.00 [5]; first, the geometry of both the projectile and the armor has been modeled with Ansys Design Modeler, and then a separate simulation of the projectile against each layer has been done. Finally, a simulation of the whole system was performed.

Ansys Explicit Dynamics with AUTODYN has been used to solve the model and generate modeling results. The materials of each part have been modeled into Ansys engineering data, and then the model properties like mesh and contact conditions between parts have been setup. Finally, the solver properties like initial conditions, system statics, and dynamic properties, and desired output have been defined.

3.2. Projectile. The projectile geometry was modeled as two parts. The inner part is the bullet core, and outer part is the bullet jacket. According to the European EN 1063 Ballistic Standards in Table 1, the assigned material to the core is the 


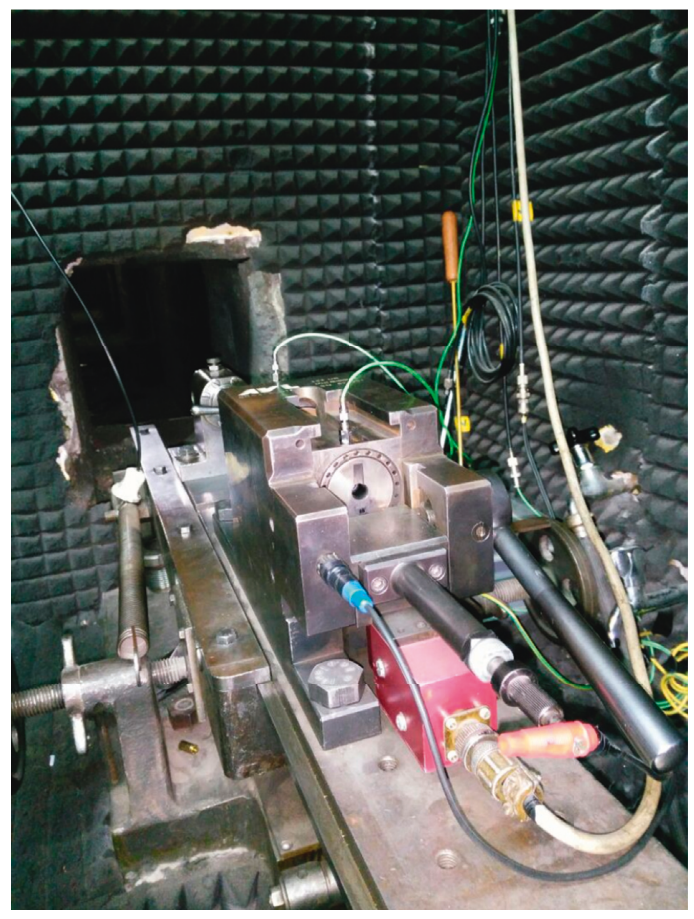

(a)

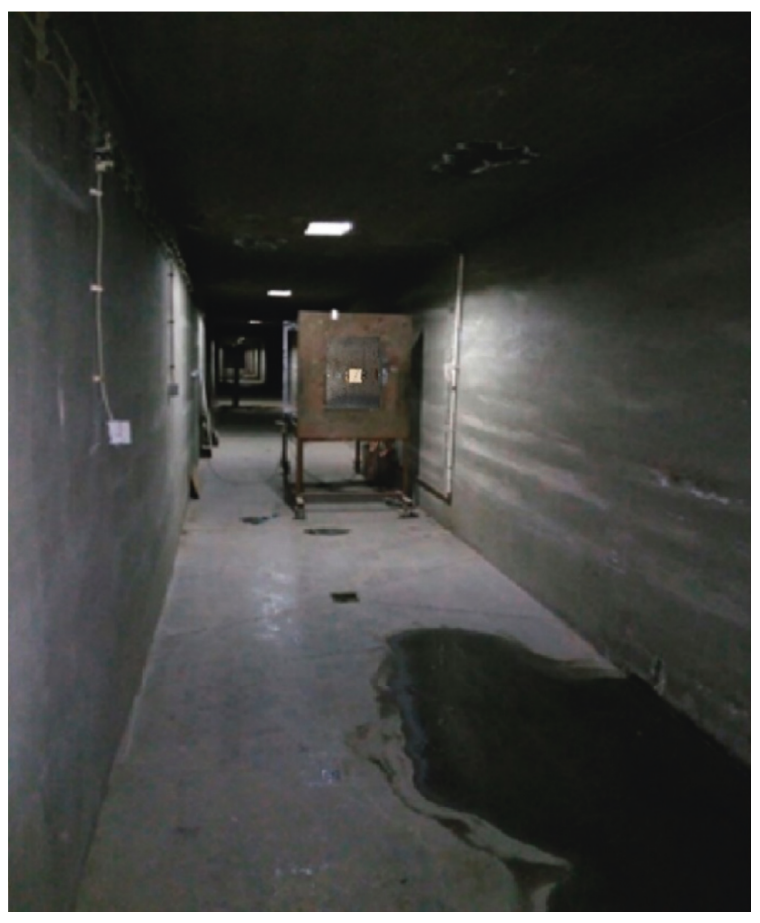

(b)

Figure 1: Images of test facility and ballistic testing mechanism.

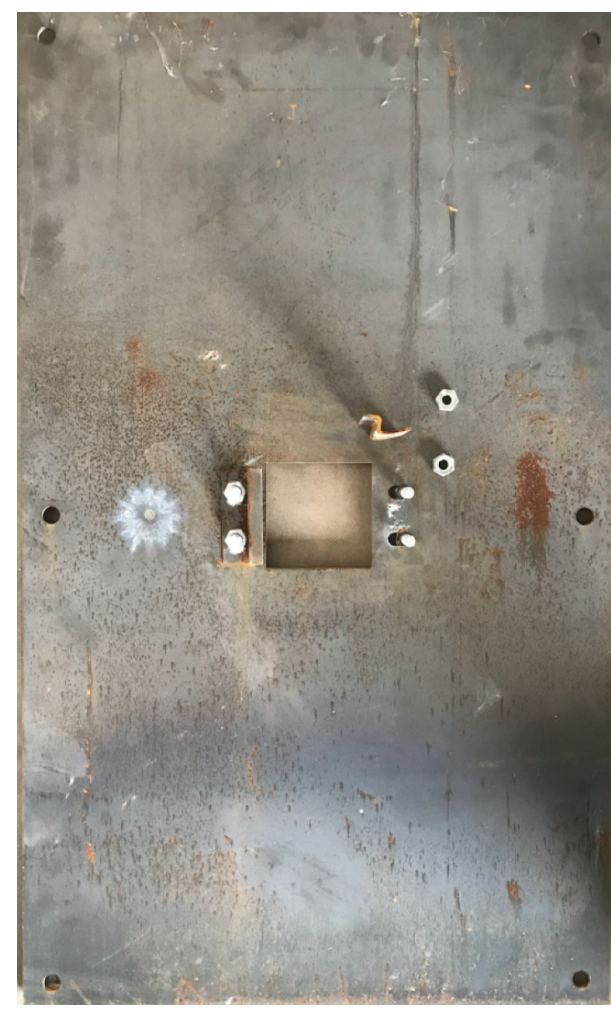

(a)

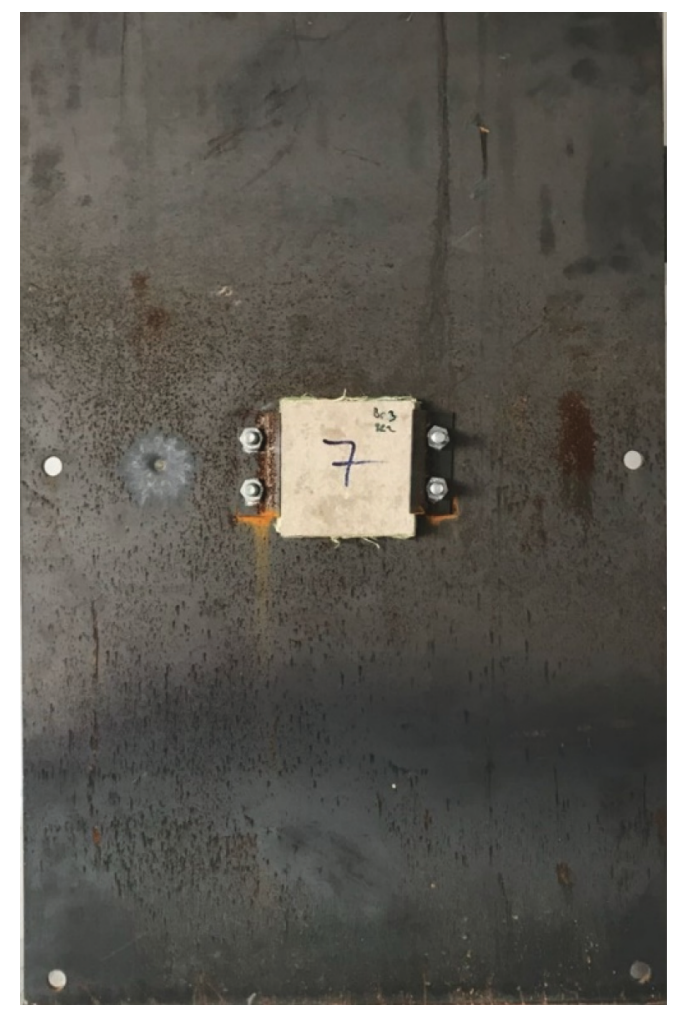

(b)

FIgUre 2: An image of the metal board $(50 \times 84 \times 3 \mathrm{~mm})$ and Z-shaped clamps. 


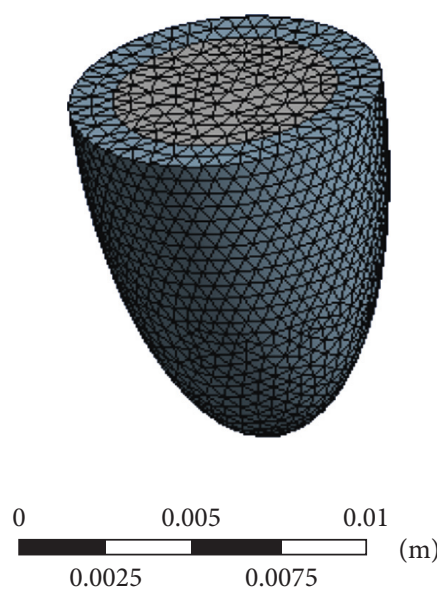

(a)

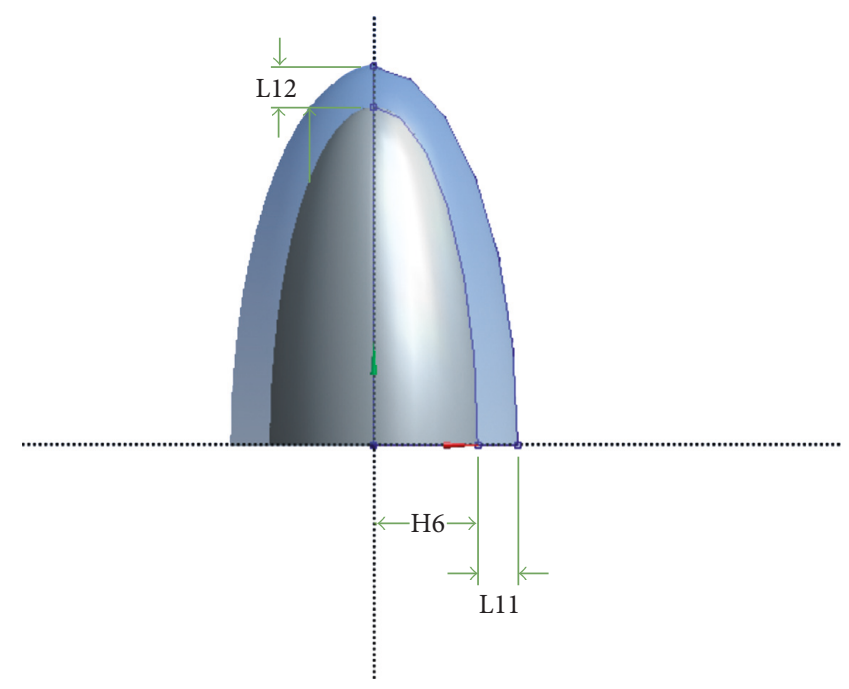

(b)

Figure 3: The representation in Ansys of the geometry and 3D mesh of the bullet.

TABLE 2: Material modeling of bullet jacket brass [11].

\begin{tabular}{|c|c|c|c|c|c|}
\hline \multicolumn{4}{|c|}{ Brass shock EOS linear } & \multirow{2}{*}{$\begin{array}{c}\text { Response } \\
\text { Shear modulus }(\mathrm{Pa})\end{array}$} & \multirow{2}{*}{$\begin{array}{c}\text { Constants } \\
\text { Density }\left(\mathrm{kg} \cdot \mathrm{m}^{-3}\right)\end{array}$} \\
\hline Gruneisen coefficient & Parameter C1 $\left(\mathrm{m} \cdot \mathrm{ts}^{-1}\right)$ & Parameter S1 & Parameter quadratic S2 $\left(\mathrm{s} \cdot \mathrm{m}^{-1}\right)$ & & \\
\hline 2.04 & 3726 & 1.434 & 0 & $4.6 e+010$ & 8450 \\
\hline
\end{tabular}

TABLE 3: Material modeling of bullet core lead [12].

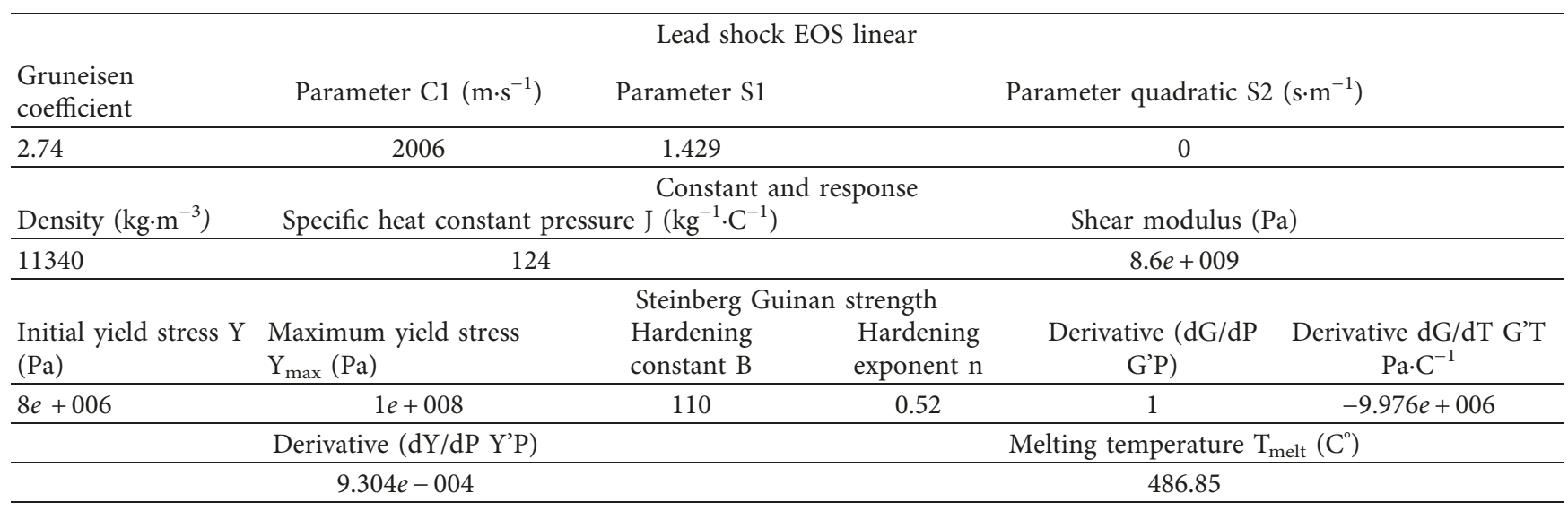

lead and the jacket is full metal (FMJ). In the simulation, the lead and the brass in the explicit material database of Ansys were assigned to the core and the jacket, respectively. Figure 3 shows the geometry and the 3D mesh of the bullet created using Ansys Explicit Dynamics mesh modeler with size multizone method and a hex-tetra element for the jacket and hex element for the core all with medium relevance center, coarse span angle center, and default element size. Both the brass and the lead have been modeled as explicit material [6]. The mechanical properties of both of these materials are shown in Tables 2 and 3, respectively.

3.3. Ballistic Armor. The armor is consisting of three layers of different materials, the fiber-cement, Kevlar woven fabrics, and the steel. Each material had to be modeled separately into Ansys material engineering data. The experimental test has been done for different samples as shown in Section 2. It was chosen to model two samples of different thicknesses for each layer to investigate the ballistic behavior of the whole system because the exact measurements of deformation and stress of the armor were difficult to obtain $[6,13]$. The geometry of the stack has been modeled into Ansys Design Modeler as solid materials with a different thickness of each layer. Samples had $x, y$ dimensions of $10 \mathrm{~cm} \times 10 \mathrm{~cm}$, and the thickness varied as follows: Sample 1 has the thickness dimensions of $8 \mathrm{~mm}$ of fiber-cement, ten layers of Kevlar fabric, and $3 \mathrm{~mm}$ thickness of the steel layer. Sample 2 has the thickness dimensions of $8 \mathrm{~mm}$ of fiber-cement, ten layers of Kevlar fabric, and $1.5 \mathrm{~mm}$ thickness of the steel layer. Sample 3 has thickness dimensions 


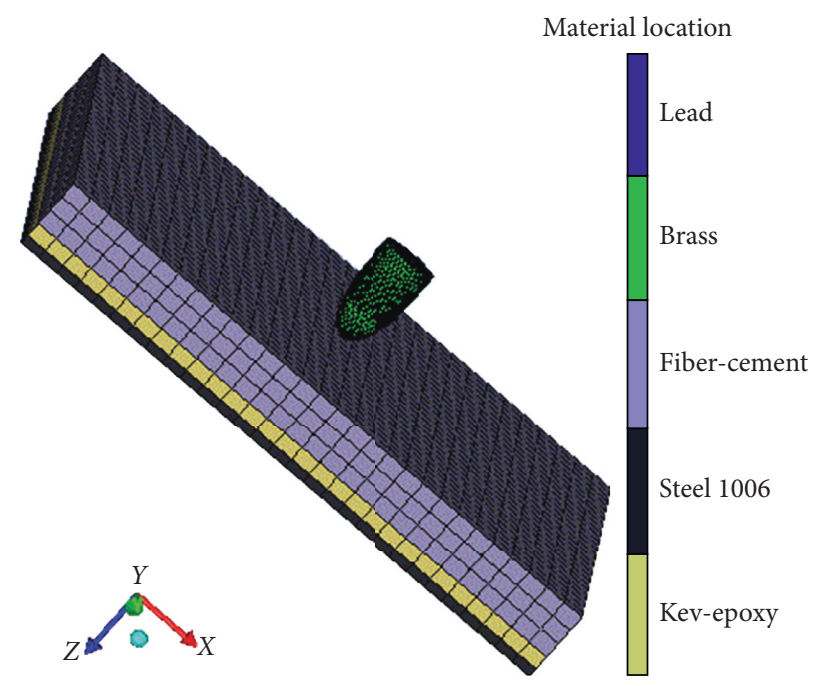

FIgURE 4: Sample 2 and the firing direction as modeled on Ansys AUTODYN.

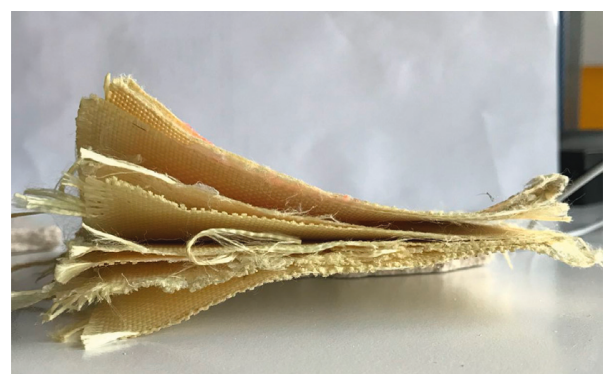

Figure 5: Geometry of 10 layers of Kevlar 29.

TABLE 4: Material modeling of fiber-cement layer.

\begin{tabular}{|c|c|c|c|c|}
\hline \multicolumn{5}{|c|}{ Isotropic elasticity } \\
\hline $\begin{array}{l}\text { Temperature } \\
\left({ }^{\circ} \mathrm{C}\right)\end{array}$ & $\begin{array}{c}\text { Young's } \\
\text { modulus (Pa) }\end{array}$ & $\begin{array}{l}\text { Poisson's } \\
\text { ratio }\end{array}$ & $\begin{array}{c}\text { Bulk } \\
\text { modulus (Pa) }\end{array}$ & $\begin{array}{c}\text { Shear } \\
\text { modulus }(\mathrm{Pa})\end{array}$ \\
\hline 25 & $7.62 e+009$ & 0.1 & $3.175 e+009$ & $3.4636 e+009$ \\
\hline & Constants & & \multirow{2}{*}{\multicolumn{2}{|c|}{$\begin{array}{l}\text { Failure response } \\
\text { Tensile ultimate } \\
\text { strength }(\mathrm{Pa})\end{array}$}} \\
\hline & Density $\left(\mathrm{kg} \cdot \mathrm{m}^{-3}\right)$ & & & \\
\hline & 1390 & & \multicolumn{2}{|c|}{$2.9 e+009$} \\
\hline \multicolumn{5}{|c|}{ Bilinear isotropic hardening } \\
\hline & Yield strength $(\mathrm{Pa})$ & & \multicolumn{2}{|c|}{ Tangent modulus $(\mathrm{Pa})$} \\
\hline & $6 e+006$ & & \multicolumn{2}{|c|}{$1.2 e+007$} \\
\hline
\end{tabular}

of $8 \mathrm{~mm}$ of fiber-cement, ten layers of Kevlar fabric, and $1 \mathrm{~mm}$ thickness of steel layer. The Kevlar layers were modeled with macrohomogeneous model that considers the whole layers are homogenous in geometry with orthotropic mechanical properties. This model is commonly used in modeling Kevlar material which gives sufficient result with limited resources [14]. Figure 4 shows sample 2 and the bullet as modeled on Ansys AUTODYN, while Figure 5 shows the geometry of Kevlar 29 layers.

3.4. Fiber-Cement. After understanding that asbestos is harmful to human health, fiber-cement sheets are made of cement mix of various natural cellulose fibers. Fiber-cement is convenient for all construction systems, easy to use and install.

In all samples, the fiber-cement layer had the same thickness of $8 \mathrm{~mm}$. In this study, it was modeled as a composite material with linear isotropic elasticity and bilinear isotropic hardening. The mechanical properties of the material have been calculated by doing 3-point tensile test [15]. Table 4 shows the modeling properties of fiber-cement layer. The mesh for the layer was created using Ansys Explicit dynamic mesh modeler as a body mesh with default element size and high smoothing. This was also applied to the other layers of the armor. Figure 4 shows the 2D mesh of the armor as a stack. 
TABLe 5: Mechanical properties of Kevlar 29. XY axes lie in the plane of the layers whereas $Z$ is perpendicular to the layer [14].

\begin{tabular}{|c|c|c|c|c|c|c|c|c|c|}
\hline \multicolumn{10}{|c|}{ Orthotropic elasticity } \\
\hline $\begin{array}{l}\text { Temperature } \\
\left({ }^{\circ} \mathrm{C}\right)\end{array}$ & $\begin{array}{c}\text { Young's } \\
\text { modulus } X \\
\text { direction }(\mathrm{Pa})\end{array}$ & $\begin{array}{c}\text { Young's } \\
\text { modulus } Y \\
\text { direction }(\mathrm{Pa})\end{array}$ & $\begin{array}{c}\text { Young's } \\
\text { modulus } Z \\
\text { direction }(\mathrm{Pa})\end{array}$ & $\begin{array}{l}\text { Poisson's } \\
\text { ratio } X Y\end{array}$ & $\begin{array}{l}\text { Poisson's } \\
\text { ratio } Y Z\end{array}$ & $\begin{array}{c}\text { Poisson's } \\
\text { ratio } X Z\end{array}$ & $\begin{array}{c}\text { Shear } \\
\text { modulus } \\
X Y(\mathrm{~Pa})\end{array}$ & $\begin{array}{c}\text { Shear } \\
\text { modulus } \\
Y Z(\mathrm{~Pa})\end{array}$ & $\begin{array}{c}\text { Shear } \\
\text { modulus } \\
X Z(\mathrm{~Pa})\end{array}$ \\
\hline 25 & $1.85 e+010$ & $1.85 e+010$ & $6 e+009$ & 0.25 & 0.33 & 0.33 & $7.7 e+008$ & $\begin{array}{l}5.43 e \\
+009 \\
\end{array}$ & $\begin{array}{l}5.43 e \\
+009\end{array}$ \\
\hline \multicolumn{10}{|c|}{ Constant and response } \\
\hline \multicolumn{5}{|c|}{1440} & \multicolumn{5}{|c|}{1420} \\
\hline \multicolumn{10}{|c|}{ Yield strengths } \\
\hline \multicolumn{5}{|c|}{ Compressive yield strength $(\mathrm{Pa})$} & \multicolumn{5}{|c|}{ Tensile yield strength $(\mathrm{Pa})$} \\
\hline \multicolumn{5}{|c|}{$1.85 e+008$} & \multicolumn{5}{|c|}{$1.85 e+009$} \\
\hline
\end{tabular}

TABLE 6: Mechanical and ballistic properties of steel 1006.

\begin{tabular}{|c|c|c|c|c|c|c|}
\hline \multicolumn{7}{|c|}{ Constant and response } \\
\hline \multicolumn{3}{|c|}{ Density $\left(\mathrm{kg} \cdot \mathrm{m}^{-3}\right)$} & \multicolumn{4}{|c|}{ Specific heat constant pressure $\left(\mathrm{J} \cdot \mathrm{kg}^{-1} \cdot \mathrm{C}^{-1}\right)$} \\
\hline \multicolumn{3}{|c|}{7896} & \multicolumn{4}{|c|}{452} \\
\hline \multicolumn{7}{|c|}{ Shock EOS linear } \\
\hline $\begin{array}{l}\text { Gruneisen } \\
\text { coefficient }\end{array}$ & \multicolumn{2}{|c|}{ Parameter $\mathrm{C} 1\left(\mathrm{~m} \cdot \mathrm{s}^{-1}\right)$} & \multicolumn{2}{|c|}{ Parameter S1 } & \multicolumn{2}{|c|}{ Parameter quadratic S2 $\left(\mathrm{s} \cdot \mathrm{m}^{-1}\right)$} \\
\hline 2.17 & \multicolumn{2}{|c|}{4569} & \multicolumn{2}{|r|}{1.49} & \multicolumn{2}{|r|}{0} \\
\hline \multicolumn{7}{|c|}{ Shear modulus $(\mathrm{Pa})$} \\
\hline $\begin{array}{l}\text { Initial yield } \\
\text { stress } \mathrm{Pa}\end{array}$ & $\begin{array}{l}\text { Hardening } \\
\text { constant } \mathrm{Pa}\end{array}$ & $\begin{array}{c}\text { Hardening } \\
\text { exponent }\end{array}$ & $\begin{array}{c}\text { Strain rate } \\
\text { constant }\end{array}$ & $\begin{array}{c}\text { Thermal softening } \\
\text { exponent }\end{array}$ & $\begin{array}{c}\text { Melting } \\
\text { temperature C }\end{array}$ & $\begin{array}{c}\text { Reference strain rate } \\
(\mathrm{sec})\end{array}$ \\
\hline $3.5 e+008$ & $2.75 e+008$ & 0.36 & $2.2 e-002$ & 1 & 1537.8 & 1 \\
\hline \multicolumn{7}{|c|}{$8.18 e+010$} \\
\hline
\end{tabular}

Source: Ansys explicit material database.

3.5. Kevlar Fabric. One of the materials used in the experimental test was Kevlar woven fabric whose mechanical properties are dependent on the geometry of yarn and the thickness of the layer [16]. It is possible to classify the fabrics used in the ballistic applications as knitted and woven fabrics. The woven fabrics are generally preferred in military areas due to their complex production methods and costs [17]. In this study, fabric direction at an angle of $\pm 45^{\circ}$ and 2D plain woven Kevlar fabric were used. Different simulations have been performed to conduct the modeling conditions of Kevlar woven fabric. In the literature, it was found that Kevlar 29, Kevlar 149, and Kevlar 49 were the most relevant materials tested as Kevlar in terms of mechanical and ballistic properties $[6,13,14]$. In stack simulation, Kevlar 29 was modeled as orthotropic elasticity mechanical properties following the MAT_054/055 composite material standard [14] which also includes fiber and matrix failure conditions $[6,14]$. Figure 5 shows the geometry of 10 layers of Kevlar 29 used in the study, and the impregnated final stack can have a total thickness of $2.4 \mathrm{~mm}$. Table 5, on the other hand, shows its mechanical properties.

3.6. Steel. Soft structural steel is easy to weld and bend. In the experimental test, S235JR steel was used as the third layer of the stack. In the simulation steel, S235JR was modeled as an explicit material with grade code SAE 1006 from Ansys

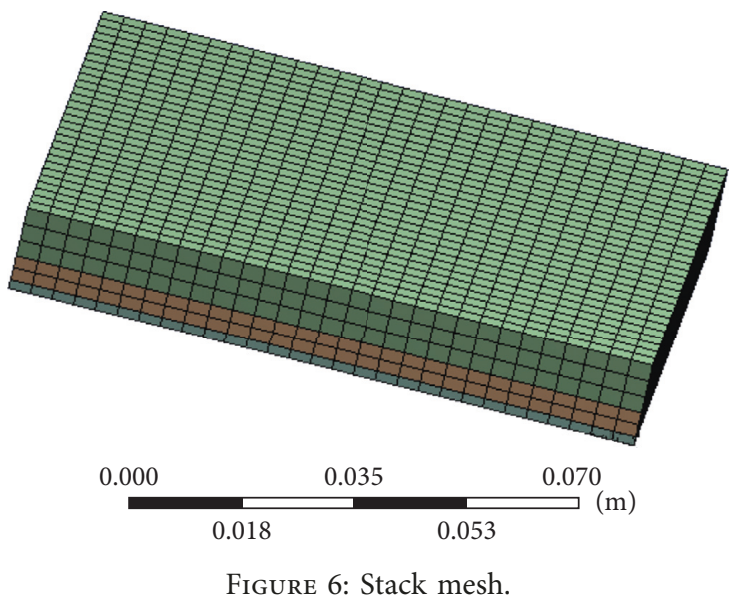

Explicit material data sources which indicates that it has the same mechanical and ballistic properties of S235JR steel [18]. Table 6 shows the mechanical and ballistic properties of steel 1006. Stack Mesh was illustrated in Figure 6.

3.7. Analysis Settings. The model has been solved in Ansys Explicit dynamics in Ansys workbench v18.2 and 19 using Ansys AUTODYN 3D solver [5, 6]. The initial condition of the test has been simulated by assigning an initial component velocity to the bullet parts equals to $400 \mathrm{~m} / \mathrm{s}$ in the $Z$ direction 

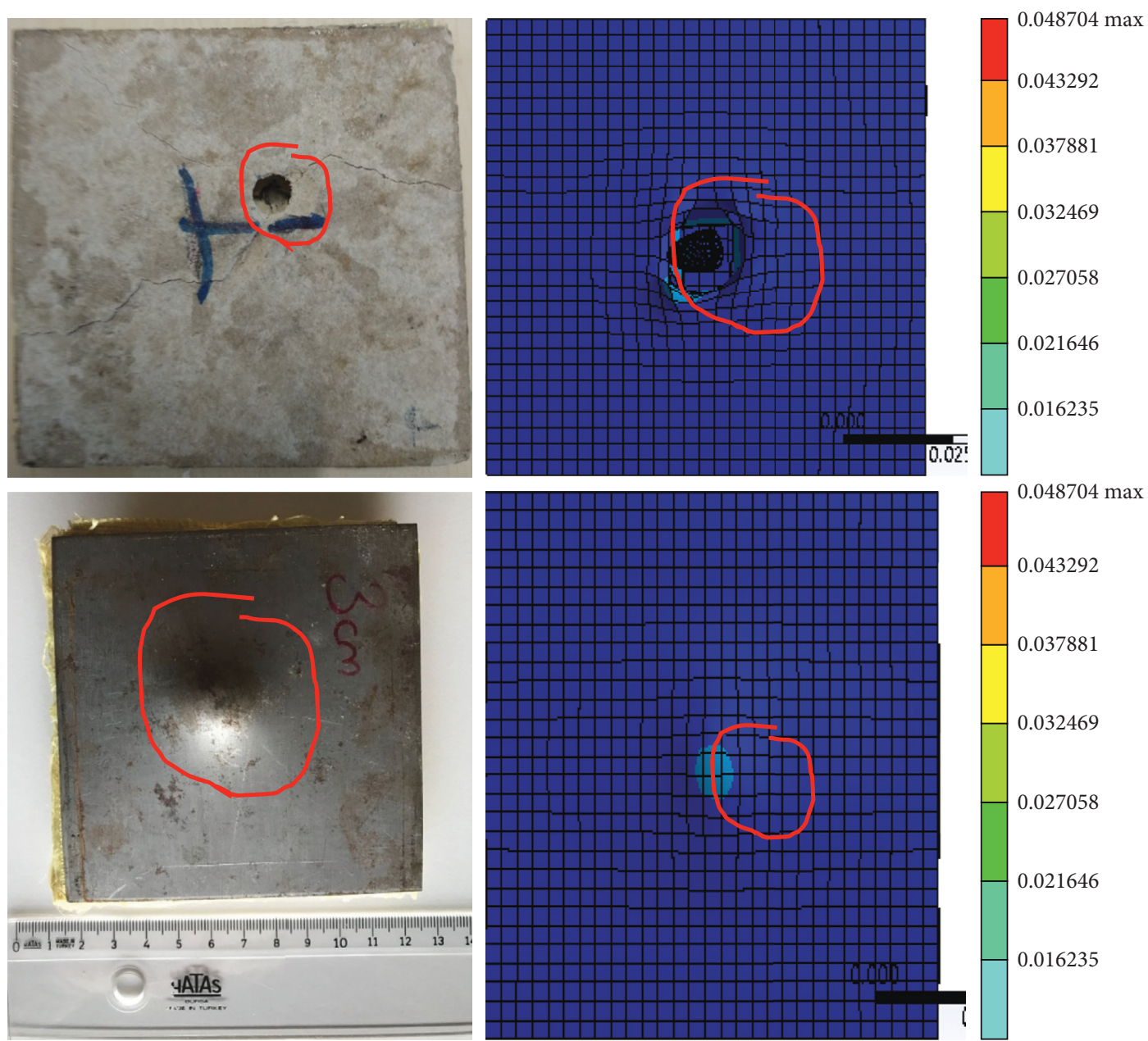

(a)

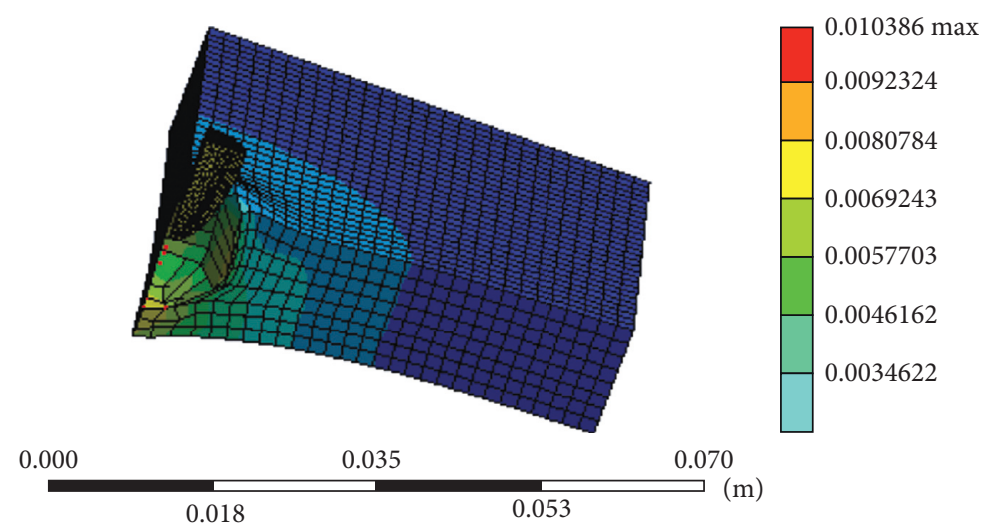

(b)

Figure 7: (a) Front and the back side of deformation of sample 1. (b) Total deformation of sample 1 as shown in experimental and simulation conditions (3D cross section of sample 1 deformation).

and fixed support boundary condition at $X$ and $Y$ faces of the stack. The end time of the analysis sets to $7 e-004 \mathrm{~s}$ with maximum number of cycles equals to $1 e+07$. Bonded contact was added between the fiber-cement layer and Kevlar layer as well as between the Kevlar layer and the steel layer in the Ansys model simulation settings to simulate the contact condition between the layers of the samples. In the literature, there are several detailed descriptions of the AUTODYN 3D code as used in explicit dynamic problems [19, 20]. However, in brief, the code solves the conservation laws of mass and momentum in Eulerian or Lagrangian-form based on boundary initial conditions. User must define the mechanical properties and failure response of the materials modeled into the code, where the program calculated and presented the 
TABLE 7: Directional deformation in $Z$ direction of steel layer of sample 1 during the time of simulation.

\begin{tabular}{lccc}
\hline Time $(\mathrm{s})$ & Minimum $(\mathrm{m})$ & Maximum $(\mathrm{m})$ & Average $(\mathrm{m})$ \\
\hline $1.1755 e-038$ & 0 & 0 & 0 \\
$3.5025 e-005$ & $-1.0591 e-005$ & $2.2814 e-003$ & $5.7685 e-005$ \\
$7.0025 e-005$ & $-6.6276 e-005$ & $6.554 e-003$ & $2.5768 e-004$ \\
$1.0506 e-004$ & $-7.5644 e-005$ & $7.6125 e-003$ & $5.2781 e-004$ \\
$1.4002 e-004$ & $-7.6373 e-005$ & $8.1679 e-003$ & $8.2409 e-004$ \\
$1.7503 e-004$ & $-1.2504 e-004$ & $8.5275 e-003$ & $1.1284 e-003$ \\
$2.1003 e-004$ & $-2.0057 e-004$ & $8.7608 e-003$ & $1.4199 e-003$ \\
$2.4503 e-004$ & $-1.1072 e-004$ & $8.8981 e-003$ & $1.6691 e-003$ \\
$2.8003 e-004$ & & $8.9576 e-003$ & $1.8495 e-003$ \\
$3.1502 e-004$ & & $8.954 e-003$ & $1.9437 e-003$ \\
$3.5 e-004$ & & $8.8967 e-003$ & $1.9528 e-003$ \\
$3.8505 e-004$ & & $8.7837 e-003$ & $1.8952 e-003$ \\
$4.2003 e-004$ & & $8.6263 e-003$ & $1.7947 e-003$ \\
$4.5502 e-004$ & & $8.446 e-003$ & $1.67 e-003$ \\
$4.9001 e-004$ & & $8.2587 e-003$ & $1.5314 e-003$ \\
$5.2506 e-004$ & & $8.0735 e-003$ & $1.3848 e-003$ \\
$5.6005 e-004$ & & $7.8903 e-003$ & $1.234 e-003$ \\
$5.9505 e-004$ & & $7.7064 e-003$ & $1.0826 e-003$ \\
$6.3005 e-004$ & & $7.5225 e-003$ & $9.3409 e-004$ \\
$6.6505 e-004$ & & $7.3395 e-003$ & $7.8644 e-004$ \\
$7.0005 e-004$ & $-1.4061 e-005$ & $7.1569 e-003$ & $6.418 e-004$ \\
\hline
\end{tabular}

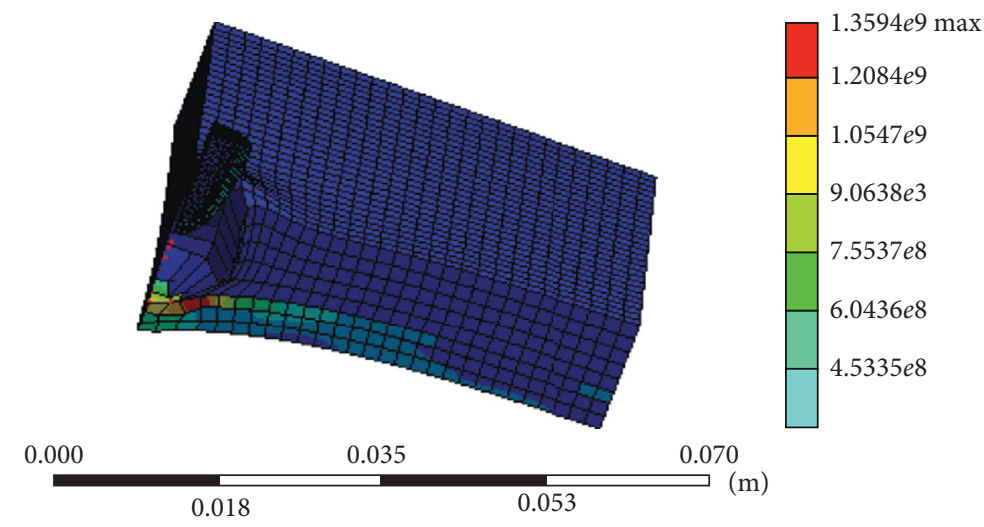

Figure 8: 3D cross section of sample 1 shows the residual stress in both the sample and the bullet.

stresses in terms of pressure, volume, and internal energy [21]. The code also has the capability of solving different types of stress including equivalent (von Mises) stress and shear stress. To predict the ballistic behavior of the system, the solver output sets to calculate total and $Z$ directional deformation of the stack layers. The mechanical properties and failure conditions have been illustrated in the material modeling section. In addition, von Mises stress was set to show the residual stress of the whole system.

\section{Results}

There are different approaches to comparing experimental and simulation ballistic test data [2]. Both the model and the experimental test could give a good indicator to the damage conditions of the armor in terms of shape and size. In addition, the simulation model could predict the total and directional deformations and shows the residual stress of the bullet and target as well.
4.1. Sample 1. Figure 7(a) shows resulting images with a deformation comparison between the experimental (on the left-hand side) and simulation (on the right-hand side) of sample 1 which indicate that the sample was able to stop the $9 \mathrm{~mm}$ FMJ bullet. Additionally, Figure 7(b) shows that the bullet goes through the fiber-cement layer and causes some deformation in the middle section of the Kevlar and steel layer of the sample. Table 7 shows the measurement of the after-impact deformation conducted by Ansys Explicit dynamics v19. Finally, the residual stress of both the bullet and stack of sample 1 is shown in Figure 8.

4.2. Sample 2. Impact test on a sample of $8 \mathrm{~mm}$ thick fibercement, 10 layers of Kevlar fabric, and $1.5 \mathrm{~mm}$ of steel layer is also simulated. Figures 9 (a) and 9(b) show the total deformation of the sample in both the experimental (on the left-hand side) and simulation (on the right-hand side) conditions, respectively. As shown in Table 8, the deformation 

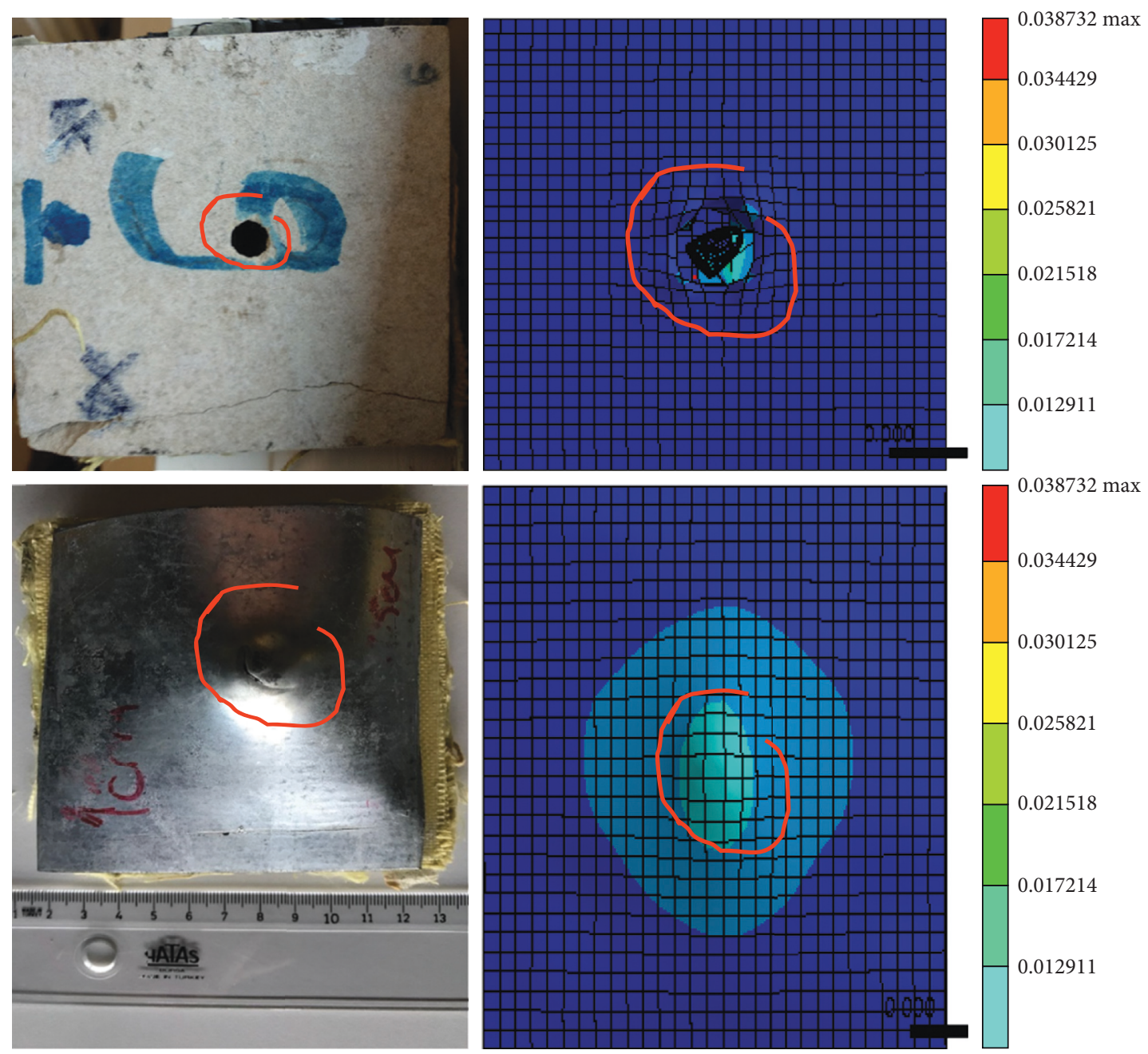

(a)

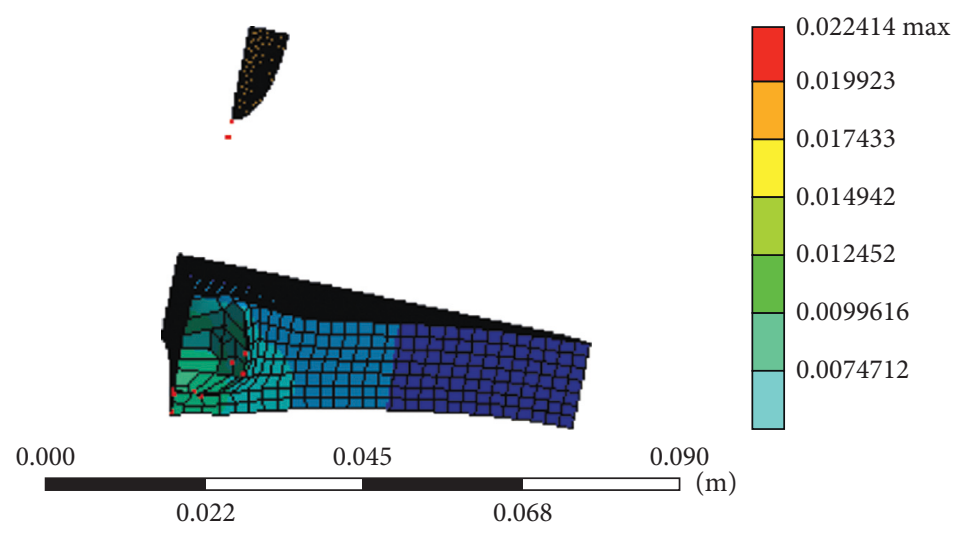

(b)

FIgUre 9: (a) Total deformation of sample 2 as shown in experimental and simulation conditions. (b) 3D cross section of total deformation of sample 2 and the $9 \mathrm{~mm}$ FMJ bullet.

of the total laminate appears to be larger than that of sample 1. Figure 10 shows the residual stresses of sample 2 and the bullet.

4.3. Sample 3. Finally, to predict the ballistic limit of the armor, a third sample was simulated. To make the comparison easier, the sample was chosen to have the same geometry of the other two samples in terms of Kevlar and the fiber-cement layer. The only change was the thickness of the steel layer which has been selected to be $1 \mathrm{~mm}$. Figure 11 shows the experimental (on the left-hand side) and simulation (on the right-hand side) results of the sample. Figure 12 shows a cross 
TABLE 8: Directional deformation in $Z$ direction of steel layer of sample 1 during the time of simulation.

\begin{tabular}{lccc}
\hline Time $(\mathrm{s})$ & Minimum $(\mathrm{m})$ & Maximum $(\mathrm{m})$ & Average $(\mathrm{m})$ \\
\hline $1.1755 e-038$ & 0 & 0 & 0 \\
$3.5056 e-005$ & $-1.3921 e-005$ & $2.9322 e-003$ & $7.9885 e-005$ \\
$7.004 e-005$ & $-7.4402 e-005$ & $8.5653 e-003$ & $3.6095 e-004$ \\
$1.0502 e-004$ & $-1.0713 e-004$ & $1.0281 e-002$ & $8.3111 e-004$ \\
$1.4002 e-004$ & $-1.0694 e-004$ & $1.131 e-002$ & $1.3797 e-003$ \\
$1.7501 e-004$ & $-8.5951 e-005$ & $1.2086 e-002$ & $1.9626 e-003$ \\
$2.1002 e-004$ & $-3.7253 e-004$ & $1.2694 e-002$ & $2.5367 e-003$ \\
$2.4505 e-004$ & $-4.4633 e-004$ & $1.3006 e-002$ & $3.0206 e-003$ \\
$2.8003 e-004$ & $-2.5738 e-004$ & $1.3004 e-002$ & $3.3204 e-003$ \\
$3.1501 e-004$ & & $1.2813 e-002$ & $3.4271 e-003$ \\
$3.5005 e-004$ & & $1.2635 e-002$ & $3.3909 e-003$ \\
$3.8502 e-004$ & 0 & $1.2606 e-002$ & $3.3043 e-003$ \\
$4.2005 e-004$ & & $1.2689 e-002$ & $3.2335 e-003$ \\
$4.5502 e-004$ & & $1.2788 e-002$ & $3.1917 e-003$ \\
$4.9006 e-004$ & & $1.2841 e-002$ & $3.1658 e-003$ \\
$5.2503 e-004$ & & $1.2848 e-002$ & $3.1412 e-003$ \\
$5.6006 e-004$ & & $1.2834 e-002$ & $3.1079 e-003$ \\
$5.9503 e-004$ & & $1.2818 e-002$ & $3.0547 e-003$ \\
$6.3001 e-004$ & & $1.2783 e-002$ & $2.9853 e-003$ \\
$6.6504 e-004$ & & $1.2739 e-002$ & $2.9168 e-003$ \\
$7.0001 e-004$ & $-3.5527 e-018$ & $1.2712 e-002$ & $2.8615 e-003$ \\
\hline
\end{tabular}

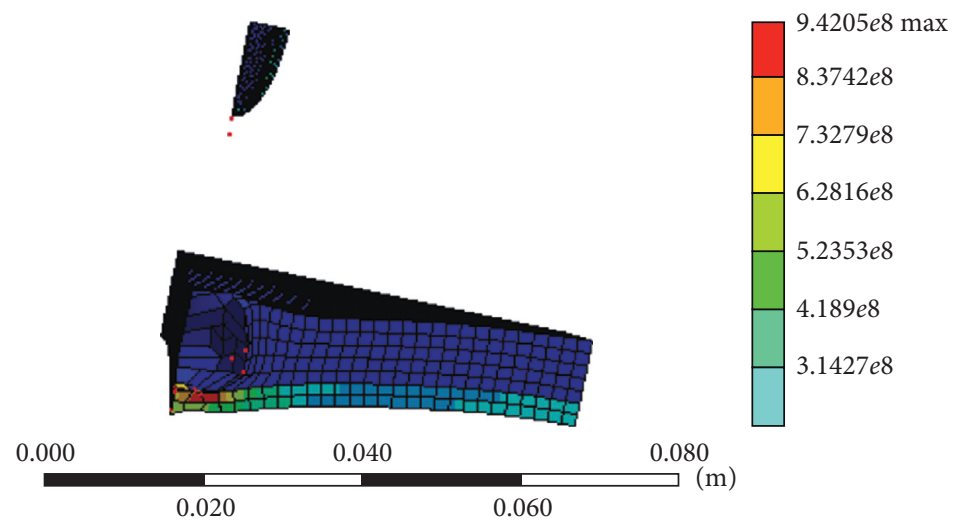

Figure 10: 3D cross section of residual stress of sample 2 and the $9 \mathrm{~mm}$ FMJ bullet.
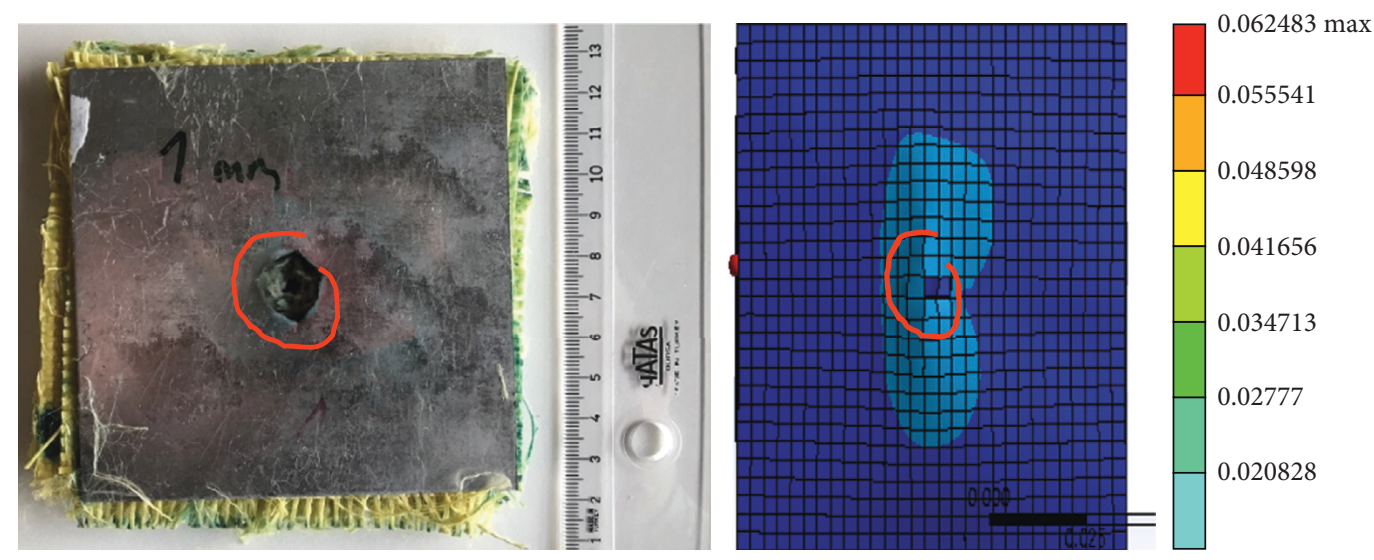

FIgURE 11: Total deformation of sample 3 as shown in experimental and simulation conditions. 


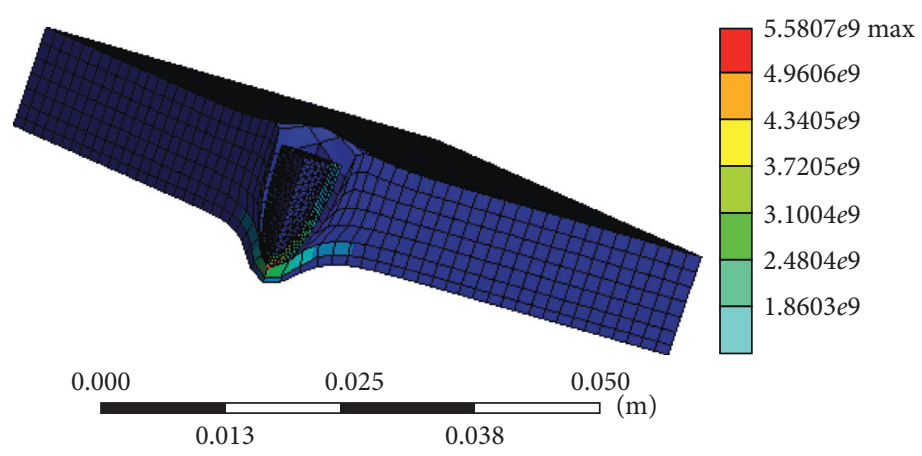

Figure 12: 3D cross section of sample 3.

section of the model of the sample which clearly indicates that the sample has failed to stop the bullet and the armor structure has been penetrated by the $9 \mathrm{~mm}$ FMJ bullet. It was demonstrated from these analytical and test results of composite structures that a thinner layer of steel was not sufficient for these types of threat levels and a larger thickness, $1.5 \mathrm{~mm}$, or higher was needed for proper protection.

\section{Conclusion}

Different materials and geometry designs were developed using composite laminate materials for ballistic structural armors. In this research, a $100 \mathrm{~cm}^{2}$ sample of a laminate plate consists of three different materials. Composite laminate structures with fiber-cement, Kevlar woven fabric, and steel layers were modeled with Ansys simulation program to investigate the technical feasibility of the armor design. Experimental testing was done on samples for validation. The result shows that a fiber-cement layer of $8 \mathrm{~mm}$ thickness, Kevlar 29 layer of $2.4 \mathrm{~mm}$ total thickness, and steel 1006 plate of $3 \mathrm{~mm}$ thickness can stop a $9 \mathrm{~mm}$ FMJ bullet with only slight deformation. Using the model, simulation can reduce expenses in the developing process of ballistic armor as it can predict the ballistic behavior and limits of the design and give significant insights through the product development process.

\section{Data Availability}

The data used to support the findings of this study are available from the corresponding author upon request.

\section{Conflicts of Interest}

The authors declare that there are no conflicts of interest regarding the publication of this paper.

\section{Acknowledgments}

This work was supported by Gebze Technical University Group, and the authors thank Ahmet Nazim at Gebze Technical University for his efforts and help.

\section{References}

[1] Michael Cohen, Laminated Armor, U.S. Patent no. 6,497,966, 2001.
[2] M. A. G. Silva, C. Cismaşiu, and C. G. Chiorean, "Numerical simulation of ballistic impact on composite laminates," International Journal of Impact Engineering, vol. 31, no. 3, pp. 289-306, 2005.

[3] A. Banerjee, S. Dhar, S. Acharyya, D. Datta, and N. Nayak, "Numerical simulation of ballistic impact of armour steel plate by typical armour piercing projectile," Procedia Engineering, vol. 173, pp. 347-354, 2017.

[4] P. M. Cunniff, "An analysis of the system effects in woven fabrics under ballistic impact," Textile Research Journal, vol. 62, no. 9, pp. 495-509, 1992.

[5] S. L. V. Shashi Kant, "A review on analysis and design of bullet resistant jacket-ballistic analysis," International Advanced Research Journal in Science, Engineering and Technology, vol. 4, pp. 1-10, 2017.

[6] C. Y. Tham, V. B. C. Tan, and H. P. Lee, "Ballistic impact of a KEVLAR ${ }^{\circledR}$ helmet: experiment and simulations," International Journal of Impact Engineering, vol. 35, no. 5, pp. 304-318, 2008.

[7] M. Saleh, L. Edwards, and I. G. Crouch, "Numerical modelling and computer simulations," in The Science of Armour Materials, pp. 483-579, Elsevier, New York, NY, USA, 1st edition, 2017.

[8] T. Belytschko, R. Gracie, and G. Ventura, "A review of extended/generalized finite element methods for material modeling," Modelling and Simulation in Materials Science and Engineering, vol. 17, no. 4, article 043001, 2009.

[9] A. Tabiei and G. Nilakantan, "Ballistic impact of dry woven fabric composites: a review," Applied Mechanics Reviews, vol. 61 , no. 1 , article $010801,2008$.

[10] A. D. Resnyansky and G. Katselis, Ballistic and Material Testing Procedures and Test Results for Composite Samples for the TIGER Helicopter Vulnerability Project, DSTO Systems Sciences Laboratory, Edinburgh, SA, Australia, 2004.

[11] W. J. Tomlinson and I. Collier, "The mechanical properties and microstructures of copper and brass joints soldered with eutectic tin-bismuth solder," Journal of Materials Science, vol. 22, no. 5, pp. 1835-1839, 1987.

[12] H. Ma and J. C. Suhling, "A review of mechanical properties of lead-free solders for electronic packaging," Journal of Materials Science, vol. 44, no. 5, pp. 1141-1158, 2009.

[13] E. Palta, H. Fang, and D. C. Weggel, "Finite element analysis of the advanced combat helmet under various ballistic impacts," International Journal of Impact Engineering, vol. 112, pp. 125-143, 2017.

[14] L. M. Bresciani, A. Manes, A. Ruggiero, G. Iannitti, and M. Giglio, "Experimental tests and numerical modelling of ballistic impacts against Kevlar 29 plain-woven fabrics with an epoxy matrix: macro-homogeneous and meso-heterogeneous 
approaches," Composites Part B: Engineering, vol. 88, pp. 114-130, 2016.

[15] A. M. Soydan, A. K. Sari, B. Duymaz, R. Akdeniz, and B. Tunaboylu, "Air-cured fiber-cement composite mixtures with different types of cellulose fibers," Advances in Materials Science and Engineering, vol. 2018, Article ID 3841514, 9 pages, 2018

[16] F. G. Carozzi, A. Bellini, T. D’Antino et al., "Experimental investigation of tensile and bond properties of carbon-FRCM composites for strengthening masonry elements," Composites Part B: Engineering, vol. 128, pp. 100-119, 2017.

[17] E. Sözen and G. Gündüz, "Composite materials and fibers used in ballistic panel and protective armor production," Journal of Faculty of Forestry B, vol. 18, pp. 194-204, 2016.

[18] Aesteiron, Mild \& Carbon Steel Plate S235jr S275jr S355jr SS400 Q235 Q345 ASTM A36 Carbon Steel Plate, AesteironSternberg, Mumbai, India, 2018, http://www.aesteiron.com/mild_steel_ carbon_steel_plates.html.

[19] G. R. Johnson and T. J. Holmquist, "An improved computational constitutive model for brittle materials," AIP Conference Proceedings, vol. 309, pp. 981-984, 1994.

[20] N. Robertson, C. Hayhurst, and G. Fairlie, "Numerical simulation of impact and fast transient phenomena using AUTODYN-2D and 3D," Nuclear Engineering and Design, vol. 150, no. 1-2, pp. 235-241, 1994.

[21] A. A. Ramadhan, A. R. Abu Talib, A. S. Mohd Rafie, and R. Zahari, "High velocity impact response of Kevlar-29/epoxy and 6061-T6 aluminum laminated panels," Materials and Design, vol. 43, pp. 307-321, 2013. 


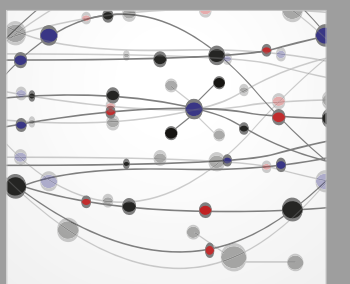

The Scientific World Journal
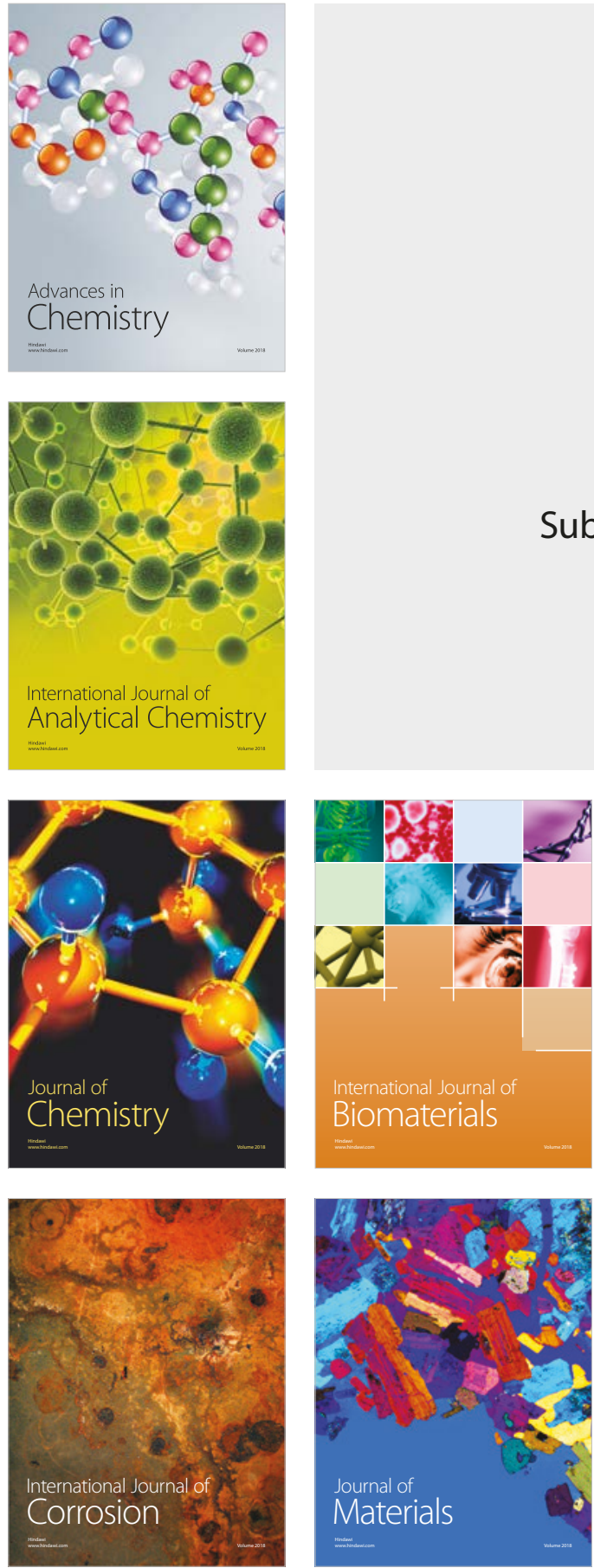

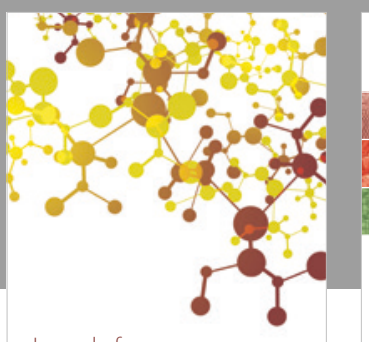

Journal of

Applied Chemistry
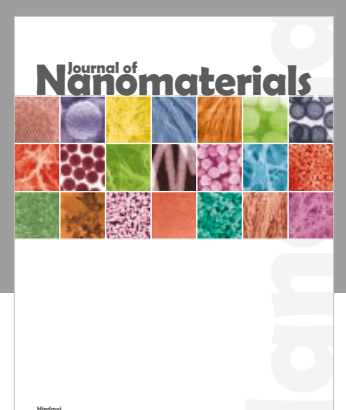

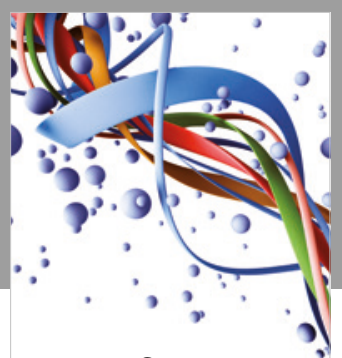

Scientifica

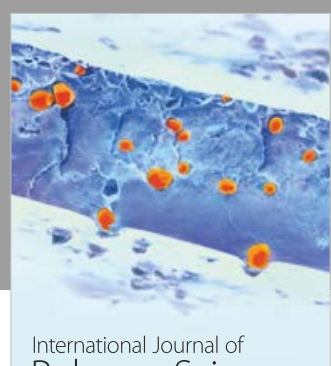

Polymer Science

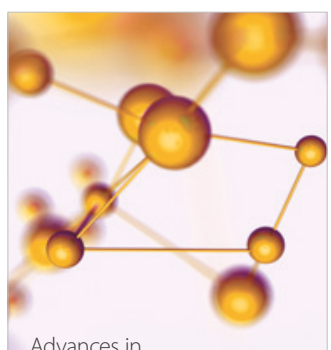

Physical Chemistry
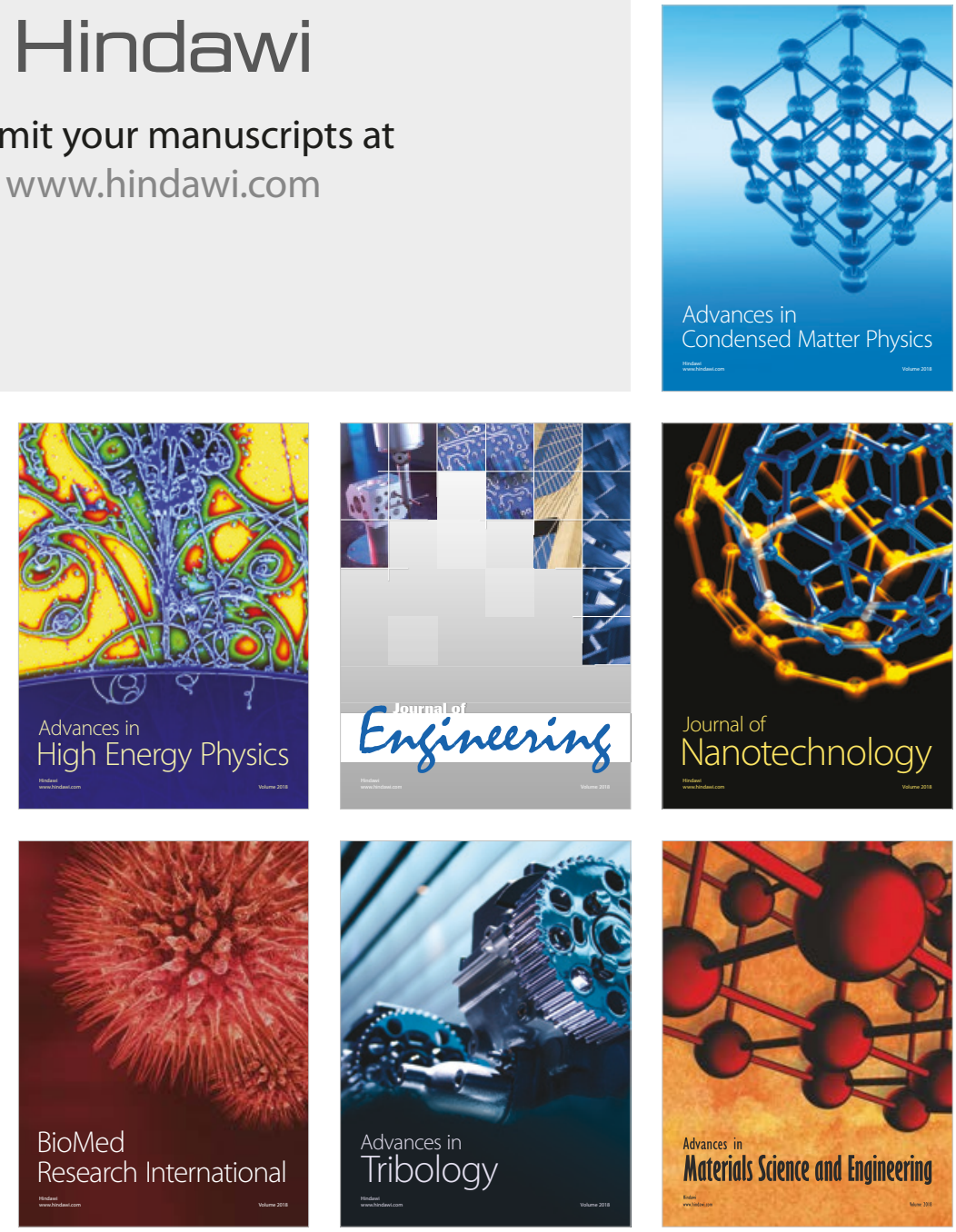